\title{
Antifungal Activity and Toxicity of the 3,4,5-Trihydroxybenzoic and 3,4,5-Tris(Acetyloxy)Benzoic Acids
}

\author{
Jéssica Pintoㅁ, Diego Silva', João Honorato², Antônio Menezes', Eugénia Pinto ${ }^{3}$, \\ Plínio Naves ${ }^{*}$ \\ ${ }^{1}$ Unit of Exact and Technological Sciences, Universidade Estadual de Goiás, Anápolis, Brazil \\ ${ }^{2}$ Department of Chemistry, Universidade Federal de São Carlos, São Carlos, Brazil \\ ${ }^{3}$ Department of Biological Sciences, Faculty of Pharmacy, Universidade do Porto, Porto, Portugal \\ Email: ${ }^{*}$ plinionaves@ueg.br
}

Received 14 April 2015; accepted 5 July 2015; published 8 July 2015

Copyright (C) 2015 by authors and Scientific Research Publishing Inc.

This work is licensed under the Creative Commons Attribution International License (CC BY).

http://creativecommons.org/licenses/by/4.0/

(c) (i) Open Access

\begin{abstract}
Invasive fungal infections have been gaining notoriety due to several factors, mainly their increasing incidence in immunocompromised patients. The aim of the present study was to evaluate the antifungal activity and toxicity of the 3,4,5-trihydroxybenzoic acid $(3,4,5-\mathrm{THB})$ and of its derivative, the 3,4,5-tris(acetyloxy)benzoic acid (3,4,5-TAB). The 3,4,5-THB was purchased and its derivative was obtained by purifying and characterizing performed using semisynthesis reactions (esterification), recrystallization, column chromatography and infrared analytical techniques and nuclear magnetic resonance. Minimum inhibitory concentration (MIC) and minimum lethal concentration (MLC) were determined in order to evaluate the antifungal activity of the compounds against four clinical isolates and four standard strains of Candida sp. and five clinical isolates of dermatophytes, following the Clinical and Laboratory Standards Institute protocols. The toxicity of the compounds was evaluated by determining the lethal dosis $\left(\mathrm{LD}_{50}\right)$ using lethality assay of Artemia salina. The most sensitive yeasts to the 3,4,5-THB were $C$. albicans ATCC 10231 and $C$. krusei ATCC 6258 , both presenting a MIC of $128 \mu \mathrm{g} \cdot \mathrm{mL}^{-1}$. For Trichophyton sp. and Epidermophyton floccosum, the MIC was $32 \mu \mathrm{g} \cdot \mathrm{mL}^{-1}$. The $3,4,5-$ TAB showed a lower inhibitory activity against Candida and dermatophyte species tested. The LD50 of 3,4,5-THB was $222.60 \mu \mathrm{g} \cdot \mathrm{mL}^{-1}$ and the $3,4,5-\mathrm{TAB}$ showed $481.69 \mu \mathrm{g} \cdot \mathrm{mL}^{-1}$ of $\mathrm{LD}_{50}$. In conclusion, the 3,4,5-trihydroxybenzoic acid showed antifungal activity against species of medical importance, mainly dermatophytosis-causing fungi, and the 3,4,5-tris(acetyloxy)benzoic acid showed no increasing antifungal activity and toxicity in relation to the original compound.
\end{abstract}

\footnotetext{
${ }^{*}$ Corresponding author.
}

How to cite this paper: Pinto, J., Silva, D., Honorato, J., Menezes, A., Pinto, E. and Naves, P. (2015) Antifungal Activity and Toxicity of the 3,4,5-Trihydroxybenzoic and 3,4,5-Tris(Acetyloxy)Benzoic Acids. Advances in Microbiology, 5, 517-522. http://dx.doi.org/10.4236/aim.2015.57053 


\section{Keywords}

\section{Antifungal, Toxicity, Candida, Dermatophytes, 3,4,5-Trihydroxybenzoic Acid, 3,4,5-Tris(Acetyloxy)Benzoic Acid}

\section{Introduction}

There has been a significant increase in reports of serious human infections associated with fungal pathogens in recent years, especially in immunocompromised patients. Although fungal infections contribute substantially to human morbidity and mortality, the impact of these diseases in human health is not widely appreciated. Among yeasts and molds, Candida and Aspergillus species are the most frequent nosocomial fungal pathogens. Mucocutaneous candidiasis, often recurrent, is also an important cause of morbidity. Nevertheless, the most common fungal diseases in humans are superficial infections of the skin, hair and nails, which affect approximately $25 \%$ of the world's population. They are predominantly caused by dermatophytes (Microsporum, Trichophyton and Epidermophyton) and affect immunocompromised and healthy persons [1]-[5].

Commercially antifungal drugs, such as polyenes and azole-derivatives, often exhibit therapeutic limitations with fungistatic mechanism of action, high toxicity, many drug interactions, insufficient bioavailability, and development of resistance or innate resistance by emerging species. Thus, it is important to continue the search for new therapeutical models [6]-[8].

Synthesis of analogs from plant secondary active and isolated metabolites contributes to obtaining new substances with medical applications. Such alterations are believed to favor changes in potency, duration and nature of the pharmacological effect, which possibly would not be observed in the original molecule, bringing many times the expected activity of the test compound [9]-[11].

The 3,4,5-trihydroxybenzoic acid is formed by condensation of two glucose metabolites, namely phosphoenolpyruvate and erythrose 4-phosphat [10]. It possesses various proven pharmacological properties, including antibacterial and antiviral activity, in addition to anti-inflammatory and antioxidant effects [12].

Esterification reactions are well-known processes which occur in acid or base media in presence of primary or secondary alcohols, most often forming stable products which can be submitted to analytical, physico-chemical and biological tests [13]. Esterification of the 3,4,5-trihydroxybenzoic acid leads to the production of the 3,4,5tris(acetyloxy)benzoic acid.

Compounds such as the 3,4,5-trihydroxybenzoic acid, previously considered as bioactive, are almost always toxic at certain concentrations. Therefore, lethality assay in a less complex living organism can be used as a quick screening in studying the biological activities of plant isolated compounds [14]. The lethality assay of Artemia salina is used in studying new bioactive molecules because such compounds are generally toxic to $A$. salina larvae and this preliminary test is characterized by its agility, reliability and simplicity in determining preliminarily the bioactivity of the compounds during isolation of natural products, the analysis being expressed in lethal dose for $50 \%$ of the population, known as $\mathrm{LD}_{50}$ [15] [16].

On the basis of the above, the objective was to analyze the in vitro antifungal activity of the 3,4,5-trihydroxybenzoic and 3,4,5-tris(acetyloxy)benzoic acids, and to calculate their $\mathrm{LD}_{50}$.

\section{Methods}

\subsection{Fungal Organisms and Artemia salina}

The antifungal activity of the compounds was evaluated against eight yeasts of the species Candida albicans ATCC 10231, C. albicans M1 and C. albicans D5; C. glabrata D10R; C. parapsilosis ATCC 90018; C. krusei ATCC 6258; C. tropicalis ATCC 13803 and C. dubliniensis CD1; and five strains of dermatophytes (Trichophyton rubrum FF5, Trichophyton mentagrophytes FF7, Epidermophyton floccosum FF9, Microsporum canis FF1 and Microsporum gypseum FF3). C. parapsilosis ATCC 90018 was used as quality control. Strains were stored in Sabouraud dextrose broth with glycerol at $-70^{\circ} \mathrm{C}$. Artemia salina (brine shrimp eggs) used for the toxicity assay were purchased from Fish Ornament feed. 


\subsection{Compounds Used in the Assays}

3,4,5-trihydroxybenzoic acid (Sigma-Aldrich) and 3,4,5-tris(acetyloxy)benzoic acid.

\subsection{Chemical Synthesis of the 3,4,5-Tris(Acetyloxy)Benzoic Acid}

The synthesis of was carried according the known as Williamson esterification reaction [17]. The 3,4,5-trihydroxybenzoic acid $(5.0 \mathrm{~g}-29 \mathrm{mmol})$ was dissolved in acetic anhydride $(10 \mathrm{~mL})$ in a medium acidified with concentrated sulfuric acid $(100 \mu \mathrm{L})$. The container was then heated in a shaking water bath $\left(60^{\circ} \mathrm{C}\right)$, with constant agitation for approximately 30 minutes; after cooling, distilled water was added to the mixture. With water addition, a white precipitate was formed, which was filtered off, washed well three times with tap water and dried under vacuum. Purification of the 3,4,5-tris(acetyloxy)benzoic acid was carried out by recrystallization: first it was dissolved in methanol to get a homogeneous mixture, which was left to rest for 3 days. The natural evaporation of the solvent caused the formation of needle-shaped crystals, which were filtered and washed with frozen methanol, to get a final mass of $6.4 \mathrm{~g}$ (yield: 73\%). For characterization, nuclear magnetic resonance (NMR) of ${ }^{1} \mathrm{H}$ was carried out in a DRX400-Bruker equipment (9.4 Tesla) and the absorption spectrum in the infrared region was obtained using the tablet method (in anhydrous $\mathrm{KBr}$ ) with a MB-102 Bomem Michelson FT spectrophotometer.

${ }^{1} \mathrm{H}$ NMR (400 MHz, $\left.\mathrm{CDCl}_{3}, 20^{\circ} \mathrm{C}\right): \delta_{\mathrm{H}} 7.88\left(2 \mathrm{H}\right.$, aromatic ring hydrogen), $\delta_{\mathrm{H}} 7.28\left(\mathrm{H}, \mathrm{CDCl}_{3}\right), \delta_{\mathrm{H}} 2.33(3 \mathrm{H}$, para-acetyl hydrogens), $\delta_{\mathrm{H}} 2.27$ (6H, meta-acetyl hydrogens).

Infrared assignments (FT-IR) $\left(\mathrm{KBr}, \mathrm{cm}^{-1}\right.$ ): 3086 (strong, carboxylic acid $\mathrm{O}-\mathrm{H}$ ), 3011 (weak, $\mathrm{vC}_{\mathrm{sp} 2 \text {-aromatic }}$ ring $\mathrm{H}$ ), 2874 (weak, $\mathrm{vC}_{\mathrm{sp} 3}$-aromatic ring $\mathrm{H}$ ), 2627, 1790 (medium, $\mathrm{v}_{\mathrm{s}} \mathrm{C}-\mathrm{O}$ acetyl), 1769 (medium, $v \mathrm{C}-\mathrm{O}-\mathrm{H}$ out of plan), 1695 (strong, $v_{\mathrm{s}} \mathrm{C}=\mathrm{O}$ acetyl), 1670, 1584, 1500 (medium, $v \mathrm{C}=\mathrm{C}$ aromatic) 1432 (strong, $\delta_{\text {ass }} \mathrm{CH}_{3}$ acetyl) and 1185 (medium, C-O acetyl). All the attributes (NMR and IR) were given as described in the literature [13].

Synthesis and purification of the 3,4,5-tris(acetyloxy)benzoic were carried out in the Chemistry Laboratory of the Exact and Technological Sciences Unit of the State University of Goiás. The nuclear magnetic resonance (RMN) experiment was carried out in the Chemistry Department of the Federal University of São Carlos.

\subsection{Antifungal Activity}

Broth microdilution protocols M27-A3 and M38-A2 [18] [19], were used to determine the minimum inhibitory concentration (MIC) of the compounds against Candida and dermatophytes respectively, in the Microbiology Laboratory of the Faculty of Pharmacy of the University of Porto.

Briefly, fungal cell suspensions were prepared from recent cultures in Sabouraud dextrose agar (SDA) according to the reference protocols. The compounds were diluted in dimethyl sulfoxide (DMSO). Two-fold serial dilutions of each compound were prepared over the range of 1024 to $64 \mu \mathrm{g} \cdot \mathrm{mL}^{-1}$ in RPMI 1640 medium before testing. Equal volumes of cell suspension and compound dilution were added in the well of a microplate and the plates incubated aerobically at $35^{\circ} \mathrm{C}$ for $48 \mathrm{~h}$ (yeasts) or at $30^{\circ} \mathrm{C}$ for five days (dermatophytes). The fungal growth was indicated by the turbidity and MICs were defined as the lowest drug concentration that reduced growth in $80 \%$ in comparison to the antifungal-free controls. To evaluate the minimum lethal concentration (MLC), $20 \mu \mathrm{L}$ aliquots were subcultured from each negative well (optically clear) and the last positive well, after MIC reading, onto SDA plates. The plates were then incubated at $35^{\circ} \mathrm{C}$ (yeasts) or $30^{\circ} \mathrm{C}$ (dermatophytes) until growth. MLC was the lowest concentration of antifungal yielding subcultures without any visible fungal growth. In addition, a reference antifungal compound, fluconazole, was used as the standard antifungal drug. Two-fold serial dilutions of fluconazole, ranging from $4-0.25 \mu \mathrm{g} \cdot \mathrm{mL}^{-1}$, were used for quality control determination by testing $C$. parapsilosis ATCC 90018. The results obtained were within the recommended limits (data not shown). All results are from three independent and concordant experiments. A range of values is presented when different results were obtained. Two growth controls, using test medium alone and with $1.0 \%(\mathrm{v} / \mathrm{v}) \mathrm{DMSO}$, and a sterility control (drug-free medium only) were included in all assays.

\subsection{Toxicity Assay with Artemia salina}

The methodology adapted was applied in the Bioassay Laboratory of the Exact and Technological Sciences Unit of the State University of Goiás [11]. In this assay, were used the artificial sea water medium, prepared by dissolving sea salt in distilled water $\left(40 \mathrm{~g} \cdot \mathrm{L}^{-1}\right)$, supplemented with yeast extract $\left(6 \mathrm{mg} \cdot \mathrm{L}^{-1}\right)$ and sterilized in autoc- 
lave. The $\mathrm{pH}$ was adjusted to 8.5 using a $0.1 \mathrm{~mol} \cdot \mathrm{L}^{-1}$ solution of $\mathrm{Na}_{2} \mathrm{CO}_{3}$. Eighty milligrams of the $A$. salina eggs were incubated for 36 hours in $1 \mathrm{~L}$ of medium with natural light, with constant room temperature and oxygenation. After eclosion, the nauplii were attracted by the light source, pipetted and transferred to a Petri dish with $5 \mathrm{~mL}$ of fresh medium. Serial dilutions of the compounds $\left(1200,600,300,150\right.$ and $\left.75 \mu \mathrm{g} \cdot \mathrm{mL}^{-1}\right)$ was maden in wells of 96-well microplates in triplicate in $100 \mu \mathrm{L}$ of artificial sea water. The nauplii were distributed in the plate, standardizing a total of $10 \pm 1$ individuals in each well. Negative, viability and lethality controls were included, and was used $100 \mu \mathrm{g} \cdot \mathrm{mL}^{-1}$ dilutions of $\mathrm{K}_{2} \mathrm{Cr}_{2} \mathrm{O}_{7}$ for lethality control. The results allowed calculation of LD50 by the probit dose-response graphical method, with the program Statplus 2009 professional (Analyst Soft). Each assay was carried out independently in triplicate.

\section{Results and Discussion}

The results obtained from the antifungal susceptibility tests, MIC and MLC, for the different compounds are shown in Table 1, the test interval was kept between $512-32 \mu \mathrm{g} \cdot \mathrm{mL}^{-1}$. For yeasts, C. albicans ATCC 10231 and C. krusei ATCC 6258 were the most sensitive species to the 3,4,5-trihydroxybenzoic acid, both presenting a MIC of $128 \mu \mathrm{g} \cdot \mathrm{mL}^{-1}$ which diverges from Leal et al., who found MIC $\geq 250 \mu \mathrm{g} \cdot \mathrm{mL}^{-1}$ for C. albicans using the same compound [20]. However, such happening is justified if one considers the nature of the tested strain, which can have exerted some influence, since other strains of C. albicans, namely M1 and D5, showed a MIC of 256 $\mu \mathrm{g} \cdot \mathrm{mL}^{-1}$. The origin of the compound used for testing can influence the results too. Among yeasts, the species least sensitive to the 3,4,5-trihydroxybenzoic acid was C. tropicalis (MIC $=512 \mu \mathrm{g} \cdot \mathrm{mL}^{-1}$ ). This result agrees with Leal et al. who found a MIC higher or equal to $250 \mu \mathrm{g} \cdot \mathrm{mL}^{-1}$ for $C$. tropicalis. In relation to the minimum lethal concentration, the 3,4,5-trihydroxybenzoic acid showed fungistatic activity being the MLCs values higher than $512 \mu \mathrm{g} \cdot \mathrm{mL}^{-1}$ for all the tested strains [20].

The 3,4,5-tris(acetyloxy)benzoic acid showed a lower inhibitory activity against Candida species than the 3,4,5-trihydroxybenzoic acid, with MIC higher or equal to $512 \mu \mathrm{g} \cdot \mathrm{mL}^{-1}$ for all tested strains, except $C$. krusei and C. albicans ATCC $10231\left(256 \mu \mathrm{g} \cdot \mathrm{mL}^{-1}\right)$, these being also the most sensitive to 3,4,5-THB. The results

Table 1. In vitro antifungal activity of the 3,4,5-trihydroxybenzoic (3,4,5-THB) and 3,4,5-tris(acetyloxy)benzoic (3,4,5TAB) acids.

\begin{tabular}{|c|c|c|c|c|}
\hline & \multicolumn{2}{|c|}{ 3,4,5-THB $\left(\mu \mathrm{g} \cdot \mathrm{mL}^{-1}\right)$} & \multicolumn{2}{|c|}{$3,4,5-\mathrm{TAB}\left(\mu \mathrm{g} \cdot \mathrm{mL}^{-1}\right)$} \\
\hline & MIC & MLC & MIC & MLC \\
\hline \multicolumn{5}{|l|}{ Yeasts } \\
\hline Candida albicans ATCC 10231 & 128 & $>512$ & 256 & $>512$ \\
\hline C. albicans M1 & 256 & $>512$ & $\geq 512$ & $>512$ \\
\hline C. albicans D5 & 256 & $>512$ & 512 & $>512$ \\
\hline C. dubliniensis CD1 & 256 & $>512$ & $\geq 512$ & $>512$ \\
\hline C. krusei ATCC 6258 & 128 & $\geq 512$ & 256 & $\geq 512$ \\
\hline C. parapsilosis ATCC 90018 & 256 & $>512$ & $\geq 512$ & $>512$ \\
\hline C. glabrata D10R & 256 & $>512$ & $256-512$ & $>512$ \\
\hline C. tropicalis ATCC 13803 & 512 & $>512$ & $>512$ & $>512$ \\
\hline \multicolumn{5}{|l|}{ Dermatophytes } \\
\hline Trichophyton rubrum FF5 & 32 & 64 & $64-128$ & 128 \\
\hline T. mentagrophytes FF7 & 32 & 64 & 128 & 128 \\
\hline Epidermophyton floccosum FF9 & 32 & 32 & 64 & $64-128$ \\
\hline Microsporum canis FF1 & 64 & 128 & $128-256$ & 256 \\
\hline M. gypseum FF3 & 64 & 128 & $128-256$ & 256 \\
\hline
\end{tabular}


Table 2. Toxic activity against Artemia salina.

\begin{tabular}{cc}
\hline Tested compounds & $\mathbf{L D}_{\mathbf{5 0}}\left(\mathbf{\mu g} \cdot \mathbf{m L}^{-\mathbf{1}}\right)$ \\
\hline 3,4,5-trihydroxybenzoic acid & 222.60 \\
3,4,5-tris(acetyloxy)benzoic acid & 481.69 \\
\hline
\end{tabular}

obtained by Leal et al. agree with our results, where all the yeasts had a MIC higher than $250 \mu \mathrm{g} \cdot \mathrm{mL}^{-1}$ for the 3,4,5-tris(acetyloxy)benzoic acid [20].

The 3,4,5-trihydroxybenzoic acid showed activity against all tested dermatophytes, the only variation being the concentration for the different species. For Trichophyton and Epidermophyton floccosum, the MIC was 32 $\mu \mathrm{g} \cdot \mathrm{mL}^{-1}$, while for Microsporum the MIC was $64 \mu \mathrm{g} \cdot \mathrm{mL}^{-1}$. Leal et al. obtained a MIC of $100 \mu \mathrm{g} \cdot \mathrm{mL}^{-1}$ of 3,4,5trihydroxybenzoic acid against $T$. rubrum. The 3,4,5-tris(acetyloxy)benzoic acid showed lesser activity in relation to the 3,4,5-trihydroxybenzoic acid, with a MIC of $64-128 \mu \mathrm{g} \cdot \mathrm{mL}^{-1}$ for Trichophyton species, and of 128 $256 \mu \mathrm{g} \cdot \mathrm{mL}^{-1}$ for Microsporum species. As usual, E. floccosum showed a higher sensitivity with a MIC value of $64 \mu \mathrm{g} \cdot \mathrm{mL}^{-1}[20]$.

In a general overview, both compounds showed antifungal activity, although varying according to studied genus and species. Unlike to what was verified for yeasts, against which the compounds were shown to be fungistatic, these were considered fungicidal against dermatophytes, due to similarity between MIC and MLC, showing at most a difference of one dilution.

The lethality assay of the compounds against $A$. salina Leach is a biological assay very useful, rapid, reliable, cheap, and widely applied for screening the acute toxicity of the compounds. The increase of mortality is proportional to the increase of concentration, characterizing linearity in the dose-effect relation of compound for determination of $\mathrm{LD}_{50}$ value [21].

The toxicity analysis using Artemia salina is shown in Table 2. Such results suggest that the 3,4,5-trihydroxybenzoic acid presents a moderate toxicity for $A$. salina larvae, whereas its derivative was shown to be less toxic, increasing the interest in developing complementary studies to verify other biological activities, besides the antifungal one.

The 3,4,5-trihydroxybenzoic acid is considered to be efficient as an anti-candida and anti-dermatophyte compound, being therefore advisable as a potential therapeutic proposal.

The replacement of the aromatic ring hydroxyls by acetyls, as presented in this work, showed no increase of effectiveness neither of the antifungal activity nor of toxicity of the used compound. So, were suggest to make other substitutions in the molecule of the 3,4,5-trihydroxybenzoic acid, seeking thus to increase the antifungal activity of these new synthetized compounds.

\section{Conclusion}

To conclude, this research suggests that both studied compounds showed antifungal and cytotoxic activity. However, the 3,4,5-trihydroxybenzoic acid must be considered more relevant for its possible use as an agent in the treatment of various fungal infections, especially infections by dermatophytes.

\section{Acknowledgements}

Pinto, J.C. thanks National Counsel of Technological and Scientific Development (CNPq) sandwich undergraduate scholarship abroad as part of the Science Without Borders Program.

Silva, D. thanks Coordination for the Improvement of Higher Level—or Education—Personnel (CAPES) master's program scholarship.

Naves, P. and Menezes, A. were supported by the Program of Scholarships Incentive to Research and Scientific Production of UEG (PROBIP)

The authors acknowledge UEG's support in drawing up the article.

\section{References}

[1] Brown, G.D., Denning, D.W., Gow, N.A.R., Levitz, S.M., Netea, M.G. and White, T.C. (2012) Hidden Killers: Human Fungal Infections. Science Translational Medicine, 4, 1-9. http://dx.doi.org/10.1126/scitranslmed.3004404 
[2] Delaloye, J. and Calandra, T. (2013) Invasive Candidiasis as a Cause of Sepsis in the Critically Ill Patient. Virulence, 5, $1-9$.

[3] Ameen, M. (2011) Epidemiology of Superficial Fungal Infections. Clinics in Dermatology, 28, 197-201. http://dx.doi.org/10.1016/j.clindermatol.2009.12.005

[4] Richardson, M.D. and Warnock, D.W. (2012) Fungal Infection: Diagnosis and Management. 4th Edition, WileyBlackwell, Oxford. http://dx.doi.org/10.1002/9781118321492

[5] Pfaller, M.A. (2012) Antifungal Drug Resistance: Mechanism, Epidemiology and Consequences for Treatment. The American Journal of Medicine, 125, 3-13. http://dx.doi.org/10.1016/j.amjmed.2011.11.001

[6] De Pauw, B.E. and Picazo, J.J. (2008) Present Situation in the Treatment of Invasive Fungal Infection. International Journal Antimicrobial Agents, 32, 167-171. http://dx.doi.org/10.1016/S0924-8579(08)70020-7

[7] Pinto, E., Vale-Silva, L., Cavaleiro, C. and Salgueiro, L. (2009) Antifungal Activity of the Clove Essential Oil from Syzygium aromaticum on Candida, Aspergillus and Dermatophyte Species. Journal Medical Microbiology, 58, 14541462. http://dx.doi.org/10.1099/jmm.0.010538-0

[8] Denning, D.W. and Hope, W.W. (2010) Therapy for Fungal Diseases: Opportunities and Priorities. Trends in Microbiology, 18, 195-204. http://dx.doi.org/10.1016/j.tim.2010.02.004

[9] Montanari, C.A. and Bolzani, V.S. (2001) Planejamento racional de fármacos baseado em produtos naturais. Quimica Nova, 24, 105-111. http://dx.doi.org/10.1590/S0100-40422001000100018

[10] Rosso, R. (2005) Avaliação das propriedades antioxidantes de derivados ésteres do ácido gálico. M.Sc. Thesis, Faculdade de Farmácia, Universidade Federal de Santa Catarina, 145 p.

[11] Molina-Salinas, G.M. and Said-Fernández, S. (2006) A Modified Microplate Cytotoxicity Assay with Brine Shrimp Larvae (Artemia salina). Pharmacologyonline, 3, 633-638.

[12] Kaur, M., Velmurugan, B., Rajamanickam, S., Agarwal, R. and Agarwal, C. (2009) Gallic Acid, an Active Constituent of Grape Seed Extract, Exhibits Anti-Proliferative, Pro-Apoptotic and Anti-Tumorigenic Effects against Prostate Carcinoma Xenograft Growth in Nude Mice. Pharmaceutical Research, 26, 2133-2140. http://dx.doi.org/10.1007/s11095-009-9926-y

[13] Silverstein, R.M, Webster, F.X. and Kiemle, D.J. (2006) Identificação Espectrométrica de Compostos Orgânicos. 7th Edition, LTC, Rio de Janeiro.

[14] Costa, E.S.S., Dolabela, M.F., Póvoa, M.M., Oliveira, D.J. and Müller, A.H. (2009) Estudos farmacognósticos, fitoquímicos, atividade antiplasmódica e toxicidade em Artemia salina de extrato etanólico de folhas de Montrichardia linifera (Arruda) Schott, Araceae. Revista Brasileira de Farmacognosia, 19, 834-838. http://dx.doi.org/10.1590/S0102-695X2009000600006

[15] Rahman, A., Choudhary, M.I. and Thomsen, W.J. (2005) Bioassay Techniques for Drug Development. Taylor \& Francis e-Library, Singapure.

[16] Nascimento, J.E., Melo, A.F.M., Lima e Silva, T.C., Veras Filho, J., Santos, E.M., Albuquerque, U.P. and Amorim, E.L.C. (2008) Estudo fitoquímico e bioensaio toxicológico frente a larvas de Artemia salina Leach. de três espécies medicinais do gênero Phyllanthus (Phyllanthaceae). Revista de Ciências Farmacêuticas Básica e Aplicada, 29, 145150.

[17] Baker, R.H. (1948) A Side Reaction in the Williamson Synthesis. Journal of the American Chemical Society, 70, 3857-3859. http://dx.doi.org/10.1021/ja01191a094

[18] CLSI-Clinical and Laboratory Standards Institute (2008) Reference Method for Broth Dilution Antifungal Susceptibility Testing of Yeasts. Approved Standard M27-A3, 3rd Edition, CLSI, Wayne, 33 p.

[19] CLSI-Clinical and Laboratory Standards Institute (2008) Reference Method for Broth Dilution Antifungal Susceptibility Testing of Filamentous Fungi. Approved Standard M38-A2, 2nd Edition, Wayne, 37 p.

[20] Leal, P.C., Mascarello, A., Derita, M., Zuljan, F., Nunes, R.J., Zacchino, S. and Yunes, R.A. (2009) Relation between Lipophilicity of Alkyl Gallates and Antifungal Activity against Yeasts and Filamentous Fungi. Bioorganic \& Medicinal Chemistry Letters, 19, 1793-1796. http://dx.doi.org/10.1016/j.bmcl.2009.01.061

[21] Parra, A.L., Yhebra, R.S., Sardiñas, I.G. and Buela, L.I. (2001) Comparative Study of the Assay of Artemia salina L. and the Estimate of the Medium Lethal Dose (LD50 Value) in Mice, to Determine Oral Acute Toxicity of Plant Extracts. Phytomedicine, 8, 395-400. http://dx.doi.org/10.1078/0944-7113-00044 